\title{
Aromatase inhibitors plus ovarian function suppression versus tamoxifen plus ovarian function suppression for premenopausal women with early stage breast cancer: a systematic review and meta-analysis
}

\author{
Jiajia Meng', Xiaolan Wang ${ }^{2}$, Yufu Guan ${ }^{3}$, Dianlong Zhang ${ }^{2}$ \\ ${ }^{1}$ Department of Breast surgery, Dalian University, Dalian, China; ${ }^{2}$ Department of Oncology, Affiliated Zhongshan Hospital of Dalian University, \\ Dalian, China; ${ }^{3}$ Department of Breast surgery, Dalian Medical University, Dalian, China \\ Contributions: (I) Conception and design: J Meng, X Wang; (II) Administrative support: D Zhang; (III) Provision of study materials or patients: Y \\ Guan; (IV) Collection and assembly of data: J Meng, Y Guan; (V) Data analysis and interpretation: J Meng, Y Guan, X Wang; (VI) Manuscript \\ writing: All authors; (VII) Final approval of manuscript: All authors. \\ Correspondence to: Dianlong Zhang. Department of Oncology, Affiliated Zhongshan Hospital of Dalian University, No. 6th Jiefang Street, Zhongshan \\ District, Dalian, China. Email: zdldoctor@163.com.
}

\begin{abstract}
In the NCCN guidelines version 1.2019, aromatase inhibitors (AIs) or tamoxifen (TAM) for 5 years plus ovarian function suppression (OFS) were recommended for premenopausal breast cancer patient who has higher risk of recurrence. The meta-analysis established a comparison of the curative effect of two adjuvant endocrine therapies. In order to obtain randomized controlled trials (RCTs) related to this metaanalysis, PubMed and Embase database were searched systematically in English during May 2019. Two reviewers screened the articles and extracted data based on the criteria recommended by the Cochrane collaboration for evaluating evidence in RCTs. The first outcome was disease-free survival (DFS). Overall survival (OS) was the other endpoint. Hazard ratios (HRs) with $95 \%$ confidence intervals (CIs) were pooled utilizing fixed-effect model. The heterogeneity of this study has been described by Cochran's Q and the $\mathrm{I}^{2}$ statistics. Three RCTs which involved 7,203 premenopausal women with breast cancer were available in this meta-analysis. Pooled HRs showed that there was not difference between AIs plus OFS and TAM plus OFS in DFS (HR $=0.87,95 \%$ CI: 0.66-1.14, $\mathrm{P}=0.30)$. No statistical differences were found in OS between the two adjuvant therapies ( $\mathrm{HR}=1.22$, 95\% CI: 0.75-1.99, $\mathrm{P}=0.43$ ). Based on the included studies, there were no statistical differences between AIs plus OFS and TAM plus OFS in DFS and OS.
\end{abstract}

Keywords: Breast cancer; tamoxifen (TAM); aromatase inhibitors (AIs); ovarian function suppression (OFS); disease-free survival (DFS)

Submitted Feb 25, 2020. Accepted for publication May 12, 2020.

doi: 10.21037/apm-20-488A

View this article at: http://dx.doi.org/10.21037/apm-20-488A

\section{Introduction}

According to the GLOBOCAN 2018 estimates of cancer incidence and mortality, 2.1 million breast cancer female patients were diagnosed and 6.3 hundred thousand person's death from breast cancer in 185 countries in 2018 (1). Regardless of patients' characteristics, cancer factors and treatment options, young breast cancer patients were more prone to have cancer metastasis, with a shorter 5 -year disease-free survival (DFS) and a higher risk of death (2-9). At present, breast cancer treatment includes surgery, neoadjuvant chemotherapy, adjuvant chemotherapy, endocrine therapy, targeted therapy and other methods. Selective estrogen receptor modulators [SERMs, e.g., 
tamoxifen (TAM)] and AIs (e.g., exemestane, letrozole, anastrozole) are included in endocrine therapy for hormone receptor positive breast cancer (10-13). TAM has been the main treatment for many years and in recent years it has become clear that ovarian function suppression (OFS) adds benefits to TAM (14) or allows the use of AI. OFS includes three methods: ovariectomy, ovarian radiotherapy and drug castration. Using gonadotropin to release hormone analogues (GnRHa, e.g., goserelin, triptorelin) was a method of castration. For premenopausal patients, goserelin plus TAM or/and chemotherapy were significantly statistical in reducing the risk of recurrence and death compared with the patients used goserelin alone (15). With the release of the outcomes of the combined analysis of the Suppression of Ovarian Function Trial (SOFT) and the Tamoxifen and Exemestane Trial (TEXT) experiments (16), the NCCN guidelines version 1.2019 considered AIs or TAM for 5 years plus OFS for premenopausal women with high-risk factors for recurrence $(17)$. Several studies $(16,18,19)$ showed the debatable results in DFS between the two therapies. The meta-analysis would explain whether the two endocrine therapies have different effects. We present the following article in accordance with the PRISMA reporting checklist (available at http://dx.doi.org/10.21037/apm-20-488A).

\section{Methods}

This meta-analysis was based on the Preferred Reporting for Systematic Reviews and Meta-Analyses (PRISMA) guidelines (20).

\section{Articles search}

We made a systematic search of database PubMed and Embase for English-language articles till May 2019, with search keywords: "Tamoxifen", "Aromatase inhibitors", "Ovarian function suppression", "Premenopausal breast cancer/carcinoma”, “'Adjuvant endocrine therapy' and 'breast cancer/carcinoma”". Additionally, mentioned articles in related conferences were screened.

\section{Screening criteria}

Articles were considered available on account of the title and abstracts. Those eligible articles were retrieved by two investigators. If the following criteria are met, this study will be included in the meta-analysis: (I) the study was randomized controlled trial; (II) included patients were consisted of premenopausal breast cancer patients who had hormone receptor positive; (III) the study had provided data of DFS; and (IV) eligible hazard ratios (HRs) and corresponding $95 \%$ confidence intervals (CIs) were provided or calculated by the study data. We will choose the latest articles, if articles are based on the same study. Besides, articles, reviews, and case reports with irrelevance or missing data were excluded.

\section{Quality assessment of the studies}

The risk of bias of all included studies was evaluated based on the Cochrane Handbook for Systematic Reviews of Interventions. Two of reviewers evaluated biases including random sequence generation, allocation concealment, blinding of participants and personnel, bling of outcome assessment, incomplete outcome data, selective reporting, and other bias. The risk bias was evaluated on three levels: low risk, high risk, and unclear (21).

\section{Data abstraction}

The following data were extracted from the included RCTs: first author's last name, published date, median age, No. of patients, surgery (yes/no), cancer stage, hormone-receptor, nodal status (positive), undergo adjuvant chemotherapy, treatment time (year), follow-up (month), end-point [DFS, overall survival (OS)], treatment regimen, HR, corresponding $95 \% \mathrm{CI}$ and $\mathrm{P}$ value. All the data were double-checked. Disagreements of reviewers were resolved though discussion.

\section{Data synthesis and analysis}

We used the Review Manager version 5.3 (The Cochrane Collaboration). Primarily, polled HRs and $95 \%$ CIs were computerized by employing the fixed-effect model (22). The statistical heterogeneity of studies was assessed by using Q and $\mathrm{I}^{2}$ statistics. It was considered heterogeneous, if a twotailed $\mathrm{P}$ value of less than 0.10 in $\mathrm{Q}$ test (23). Because the small number of studies are included in this meta-analysis, the intensity and sensitivity of Q test were low, so $\mathrm{I}^{2}$ value was also used. $\mathrm{I}^{2}$ values the range data between $0 \%$ to $100 \%\left(\mathrm{I}^{2}=0-25 \%\right.$, no heterogeneity; $\mathrm{I}^{2}=25-50 \%$, moderate heterogeneity; $\mathrm{I}^{2}=50-75 \%$, large heterogeneity; and $I^{2}=75-100 \%$, extreme heterogeneity) (21). The fixed-effect model will be employed, if heterogeneity exists $\left(\mathrm{I}^{2}>50 \%\right)$; conversely, the random-effects model is applied (24). 


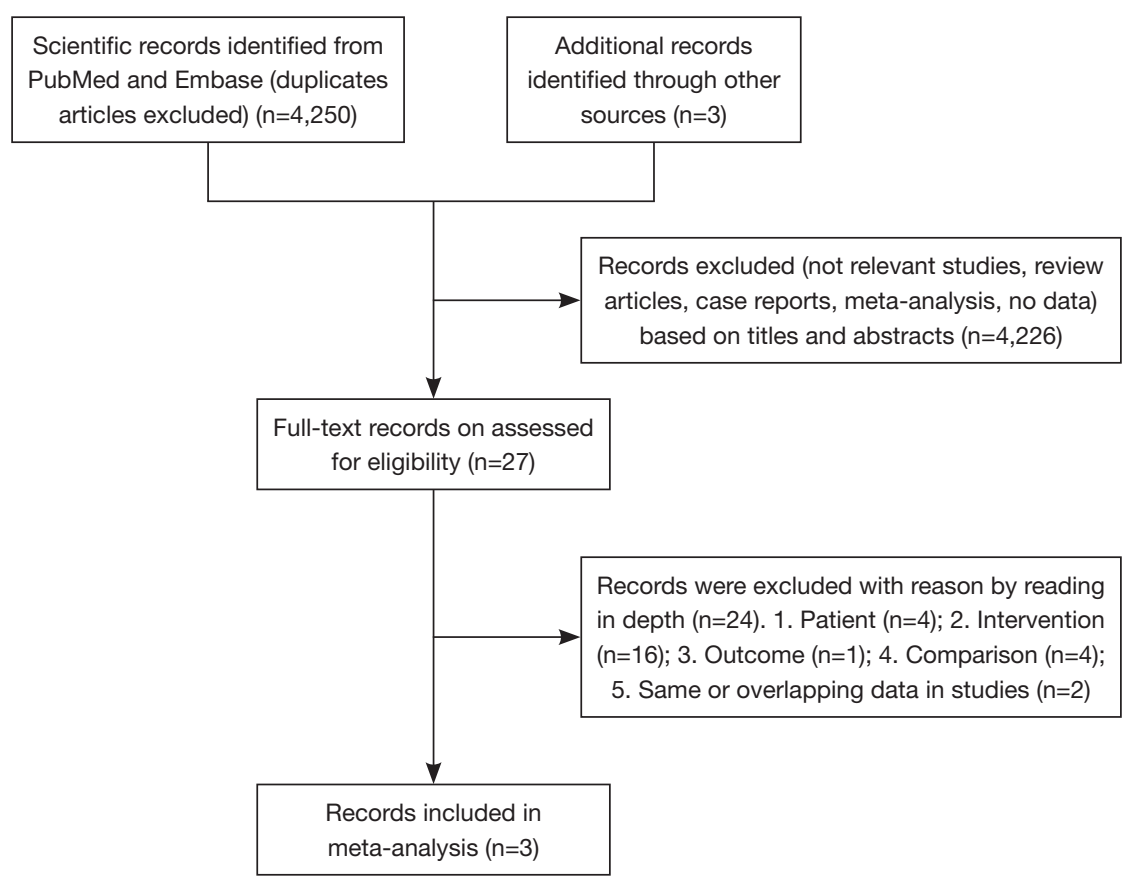

Figure 1 Summary of the studies selection process.

And we will use sensitivity analysis to identify sources of heterogeneity. If $\mathrm{P}$ value is less than 0.05 , it can be regarded as a statistically significant result.

\section{Results}

\section{Study identification and selection}

We found 4,250 articles in PubMed and Embase database search, and found 3 records through other sources. Firstly, 4,226 articles (non-related studies, review articles, case reports, meta-analysis, no data) were excluded based on titles and abstracts. And 24 records were excluded by reading in depth the following reasons: (I) patients ( $n=4)$; (II) intervention ( $\mathrm{n}=16)$; (III) outcome $(\mathrm{n}=1)$; (IV) comparison $(\mathrm{n}=4)$; (V) same or overlapping data in studies $(\mathrm{n}=2)$. Finally, only 3 records with 7,203 patients were included in this study. The literature selection process is presented in a flow chart in Figure 1.

\section{Risk of bias assessment}

The risk of bias is summarized in Figures 2,3. The reporting biases of all included studies $(18,25,26)$ were unclear risk. All studies' performance biases were high risk. The attrition bias of the Perrone 2019 trial was high risk (18). The other risk of biases in all included studies were low risk.

\section{Characteristics of the studies}

Table 1 describes the traits of the included study. Francis, Pagani's 2018 study was a comprehensive analysis of data from the SOFT and TEXT. In this study, patients received triptorelin (3.75 mg every 28 days) and TAM (20 $\mathrm{mg}$ per day) or exemestane $(25 \mathrm{mg}$ per day) for 5 years. However, in the TEXT experiment, some patients received bilateral oophorectomy or ovarian radiotherapy (16). The study of Perrone 2019, HOBOE-2, was also phase 3 trial. In this study, patients received triptorelin ( $3.75 \mathrm{mg}$ every 28 days) and TAM (20 $\mathrm{mg}$ per day) or letrozole (2.5 $\mathrm{mg}$ per day) with or without zoledronic acid (4 mg every 6 months) for 5 years (18). Totally, 7,203 patients were premenopausal women with hormone receptor positive early breast cancer, all of patients who received surgery before enrollment. The positive rates of lymph nodes were $45 \%, 42 \%$ and $33 \%$ respectively in 3 studies, and $63 \%$ and $57 \%$ of patients received neoadjuvant or adjuvant chemotherapy in studies of HOBOE-2 and Francis, Pagani 2018. In ABCSG-12, the number of patients receiving adjuvant chemotherapy was zero, and the proportion of patients receiving chemotherapy before surgery was probably $5.37 \%$. 
Random sequence generation (selection bias)

Allocation concealment (selection bias)

Blinding of participants and personnel (performance bias)

Blinding of outcome assessment (detection bias)

Incomplete outcome data (attrition bias)

Selective reporting (reporting bias)

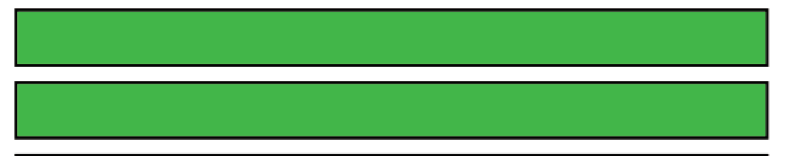

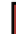
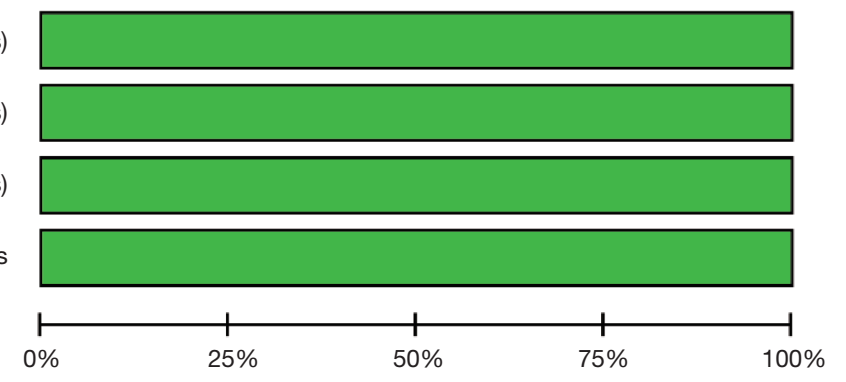

Low risk of bias

Unclear risk of bias

High risk of bias

Figure 2 Risk of bias graph according to the Cochrane Handbook for Systematic Reviews of Interventions in the included studies.

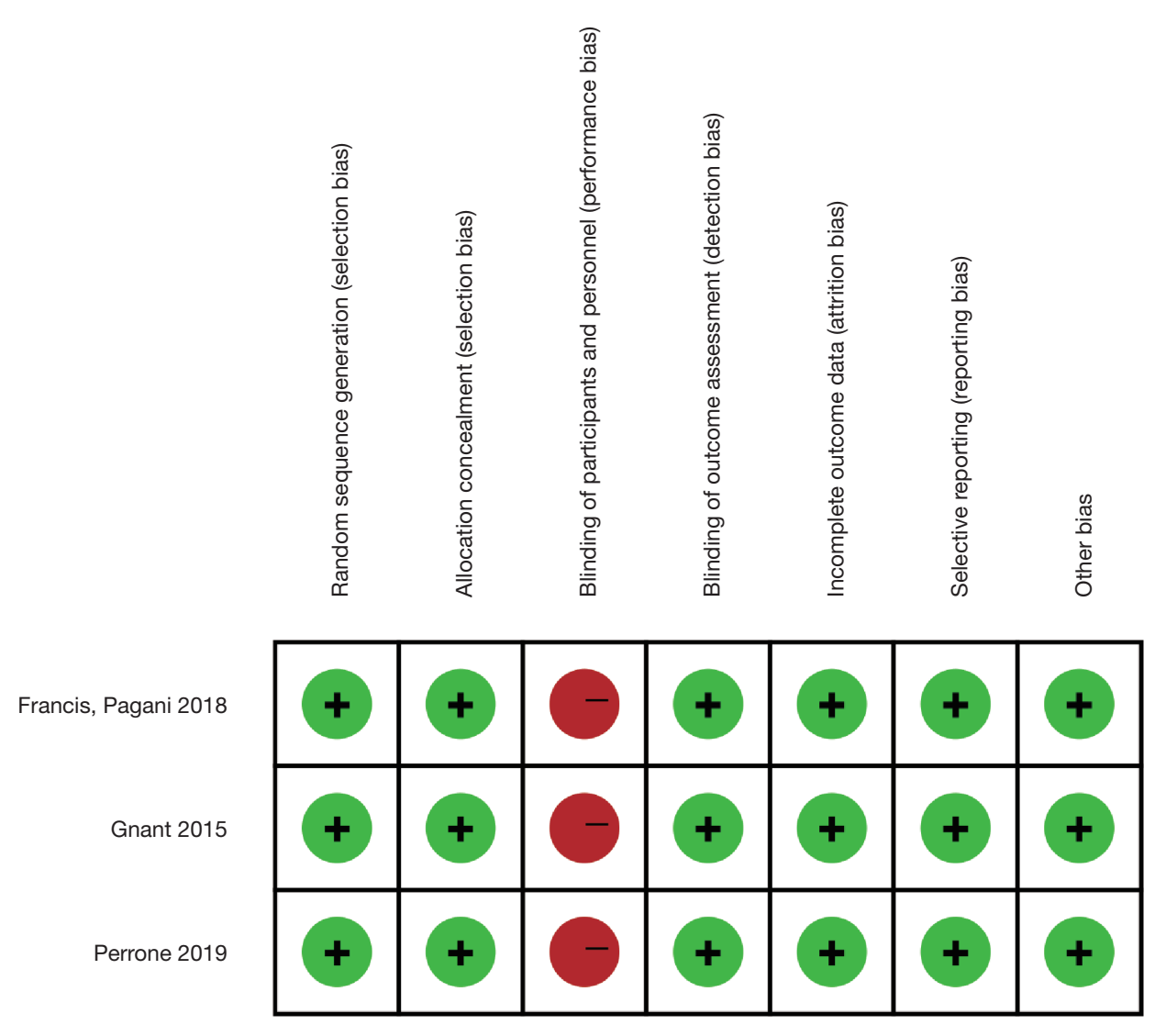

Figure 3 Risk of bias summary. 
Table 1 Characteristics of included studies

\begin{tabular}{|c|c|c|c|}
\hline Variable & \multicolumn{3}{|c|}{ Study } \\
\hline Median age (years) & 45 & 42 & 45 \\
\hline No. of patients & 711 & 4,690 & 1,803 \\
\hline Surgery (yes/no) & Yes & Yes & Yes \\
\hline Hormone-receptor & $\mathrm{ER}(+) / \mathrm{PR}(+)$ & $\mathrm{ER}(+) / \mathrm{PR}(+)$ & $\mathrm{ER}(+) / \mathrm{PR}(+)$ \\
\hline Nodal status (positive) & $45 \%$ & $42 \%$ & $33 \%$ \\
\hline Undergo chemotherapy & $63 \%$ & $57 \%$ & $5.38 \%$ \\
\hline Treatment time (year) & 5 & 5 & 3 \\
\hline \multirow[t]{2}{*}{ Treatment regimen } & $\mathrm{L}+\mathrm{OFS}$ vs. T+OFS & $\mathrm{E}+\mathrm{OFS}$ vs. T+OFS & $\mathrm{L}+\mathrm{OFS} /+\mathrm{Z}$ vs. $\mathrm{T}+\mathrm{OFS} /+\mathrm{Z}$ \\
\hline & $\mathrm{L}+\mathrm{OFS}+\mathrm{Z}$ vs. $\mathrm{L}+\mathrm{OFS}$ & - & $\mathrm{L} / \mathrm{T}+\mathrm{OFS}+\mathrm{Z}$ vs. $\mathrm{L} / \mathrm{T}+\mathrm{OFS}$ \\
\hline \multirow[t]{2}{*}{ Hazard ratio (DFS, OS) } & $0.72,-$ & $0.77,0.98$ & $1.13,1.63$ \\
\hline & $0.70,-$ &,-- & $0.77,0.66$ \\
\hline \multirow[t]{2}{*}{$95 \% \mathrm{Cl}$ (DFS, OS) } & $0.48-1.07,-$ & $0.67-0.90,0.79-1.22$ & $0.88-1.45,1.05-2.52$ \\
\hline & $0.44-1.12,-$ &,-- & $0.60-0.99,0.43-1.02$ \\
\hline \multirow[t]{2}{*}{$P$ value (DFS, OS) } & $0.06,-$ & $<0.001,0.84$ & $0.335,0.03$ \\
\hline & $0.22,0.14$ &,-- & $0.042,0.064$ \\
\hline
\end{tabular}

OS, overall survival; PR, progesterone receptor; DFS, disease-free survival; E, exemestane; ER, estrogen receptor; L, letrozole; OFS, ovarian function suppression; T, tamoxifen; Z, zoledronic acid.

\section{Meta-analysis results}

Three RCTs with 7,203 premenopausal breast cancer were included in this meta-analysis.

\section{Disease-free survival}

The results are represented by forest plots in Figure 4 . There was statistical heterogeneous in those studies $(\mathrm{P}=0.03$, $\mathrm{I}^{2}=72 \%$ ), so the data were calculated by using random-effect model. Pooled HRs shows that there was no significantly statistical difference in OS among women who received OFS plus AIs or TAM (HR =0.87, 95\% CI: 0.66-1.14, $\mathrm{P}=0.30)$.

\section{OS}

Two articles with 6,493 patients showed the relationship between OFS plus AIs or TAM. We used random-effect model because of heterogeneous $\left(\mathrm{P}=0.04, \mathrm{I}^{2}=76 \%\right)$. There was no significantly statistical difference in OS among women who received OFS plus AIs or TAM $(\mathrm{HR}=1.22$, 95\% CI: 0.75-1.99, $\mathrm{P}=0.43$ ) in Figure 5.

\section{Sensitivity analysis}

Sensitivity analysis showed that one individual study had excessive influence on the results. After we removed this article (ABCSG-12), we conducted data analysis and found that heterogeneity disappeared $\left(\mathrm{P}=0.71, \mathrm{I}^{2}=0 \%\right)$. The result of two studies indicated that AIs plus OFS could improve DFS, compared with TAM plus OFS (HR $=0.77,95 \% \mathrm{CI}$ : 0.67-0.88, $\mathrm{P}=0.0002$ ) in Figure 6.

\section{Discussion}

This is the first meta-analysis to study whether there are differences between TAM plus OFS and AIs plus OFS. 


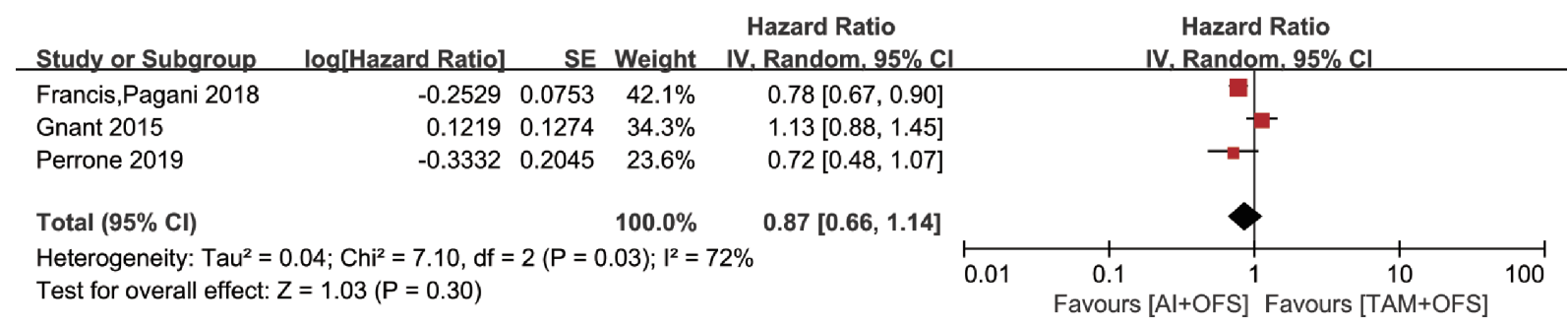

Figure 4 Forest plot analysis of patients received aromatase inhibitors plus ovarian function suppression versus tamoxifen plus ovarian function suppression in disease-free survival. CI, confidence interval; AI, aromatase inhibitor; OFS, ovarian function suppression; TAM, tamoxifen.

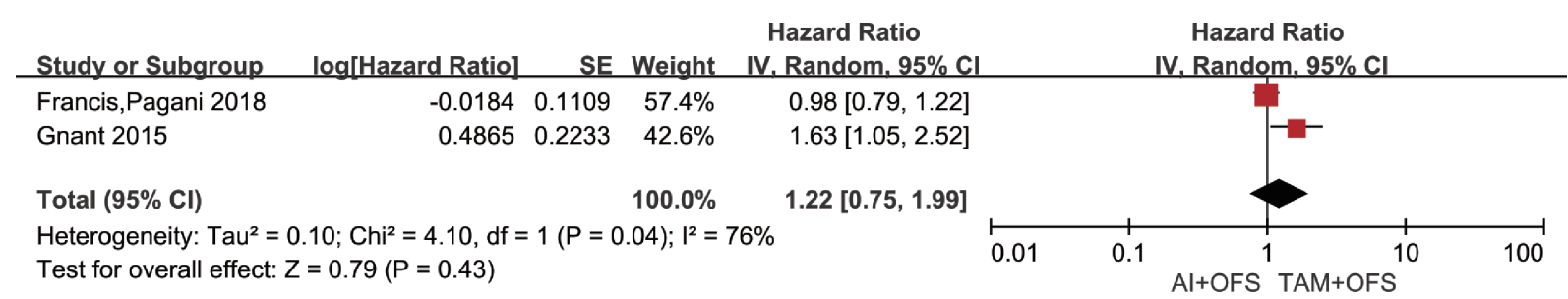

Figure 5 Forest plot analysis of patients received aromatase inhibitors plus ovarian function suppression versus tamoxifen plus ovarian function suppression in overall survival. CI, confidence interval; AI, aromatase inhibitor; OFS, ovarian function suppression; TAM, tamoxifen.

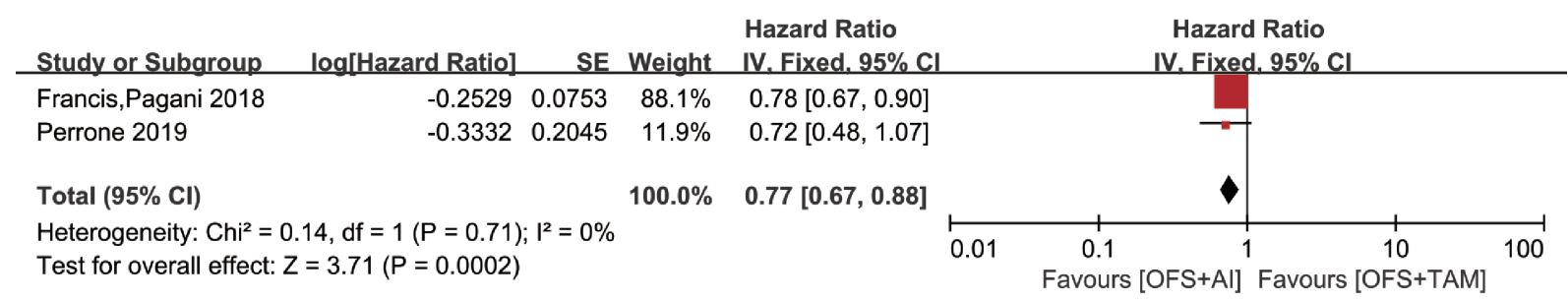

Figure 6 Sensitivity analysis (the ABCSG12 was excluded). CI, confidence interval; AI, aromatase inhibitor; OFS, ovarian function suppression; TAM, tamoxifen.

The result of three studies indicated that there was not difference between TAM plus OFS and AIs plus OFS in DFS for premenopausal women with early stage breast cancer. And the result of two studies showed that there was not statistical difference between the two endocrine therapies in OS. The statistical heterogeneity was found in this meta-analysis. The designs differences of three trials were the reasons of heterogeneity. In ABCSG-12 trial, patients received endocrine therapy for 3 years (19), it would reduce the effects compared with who received same therapy for 5 years. Furthermore, zoledronic acid played a significant role in improving DFS (27) in this study based on the comprehensive analysis of ABCSG-12 and HOBOE-2 trials. It showed that the combination of zoledronic acid and endocrine therapy was more important than single endocrine therapy (HR $=0.75,95 \%$ CI: $0.60-0.94)(18,19)$. In addition, the ABCSG-12 and HOBOE-2 trials were followed up for less than 8 years $(18,19)$. The results of 10-year follow-up of ATAC study showed that compared with TAM group, AI group showed better results in terms of DFS, recurrence time and distant recurrence time $(\mathrm{P}=0.04, \mathrm{P}=0.001, \mathrm{P}=0.03)$ in both the total study population and hormone receptor positive population (28). And in SOFT trial, AIs plus OFS did not improve DFS when it 
was followed up for 5 years (29). However, the group of AIs plus OFS had a better outcome of DFS after followup duration of 8 years (16). It was found that the group of AIs plus OFS had a better DFS, when the ABCSG-12 was removed. Consequently, it is probable that good results will be found with longer follow-up duration. There was other study that TAM or AI combined with OFS were applied to 204 patients before operation. They were randomly divided into TAM combined with OFS group and AI combined with OFS group. After 24 weeks of follow-up, the complete or partial remission rate of AI combined with OFS group was significantly better than that of the other group (95\% CI: 6.5-33.3, $\mathrm{P}=0.004$ ) (30). May be the endocrine therapy with AIs plus OFS not only bring benefits to postoperative patients, but also improve the complete or partial remission rate of preoperative patients.

Some studies indicated that AIs plus OFS would increase the rate of side effects $(31,32)$, but the same things happened to the group of TAM plus OFS due to suppressed ovarian function (33). It should be emphasized that premenopausal patients with advanced or metastatic breast cancer could get benefit from AIs plus OFS $(34,35)$. Although it is premature to recommend AIs combined with OFS for premenopausal breast cancer patients, AIs plus OFS are worth being a first-line endocrine therapies for high-risk premenopausal patients [e.g., under 35 years old (36) compared with TAM plus OFS].

This meta-analysis also has some shortcomings. First of all, because the inclusion standard of this study was randomized clinical trials, only three studies were included. Although there were many cases, there were also relatively few research samples. Second, because some studies did not provide enough information, further sub-component analysis could not be conducted, and the influence of patient age, TNM stage, histological grade and other factors on the results could be obtained.

\section{Conclusions}

There were no statistical differences between AI plus OFS and TAM plus OFS in DFS and OS for premenopausal women with early stage breast cancer. However, the amount of literature in this meta-analysis was small, so the research needed more evidence to support the conclusion.

\section{Acknowledgments}

Funding: None.

\section{Footnote}

Reporting Checklist: The authors have completed the PRISMA reporting checklist. Available at http://dx.doi. org/10.21037/apm-20-488A

Conflicts of Interest: All authors have completed the ICMJE uniform disclosure form (available at http://dx.doi. org/10.21037/apm-20-488A). The authors have no conflicts of interest to declare.

Ethical Statement: The authors are accountable for all aspects of the work in ensuring that questions related to the accuracy or integrity of any part of the work are appropriately investigated and resolved.

Open Access Statement: This is an Open Access article distributed in accordance with the Creative Commons Attribution-NonCommercial-NoDerivs 4.0 International License (CC BY-NC-ND 4.0), which permits the noncommercial replication and distribution of the article with the strict proviso that no changes or edits are made and the original work is properly cited (including links to both the formal publication through the relevant DOI and the license). See: https://creativecommons.org/licenses/by-nc-nd/4.0/.

\section{References}

1. Bray F, Ferlay J, Soerjomataram I, et al. Global cancer statistics 2018: GLOBOCAN estimates of incidence and mortality worldwide for 36 cancers in 185 countries. CA Cancer J Clin 2018;68:394-424.

2. Owrang M, Copeland RL Jr, Ricks-Santi LJ, et al. Breast Cancer Prognosis for Young Patients. In Vivo 2017;31:661-8.

3. Lian W, Fu F, Lin Y, et al. The Impact of Young Age for Prognosis by Subtype in Women with Early Breast Cancer. Sci Rep 2017;7:11625.

4. Anders CK, Hsu DS, Broadwater G, et al. Young age at diagnosis correlates with worse prognosis and defines a subset of breast cancers with shared patterns of gene expression. J Clin Oncol 2008;26:3324-30.

5. Anders CK, Johnson R, Litton J, et al. Breast cancer before age 40 years. Semin Oncol 2009;36:237-49.

6. El Saghir NS, Seoud M, Khalil MK, et al. Effects of young age at presentation on survival in breast cancer. BMC Cancer 2006;6:194.

7. Fredholm H, Eaker S, Frisell J, et al. Breast cancer in 
young women: poor survival despite intensive treatment. PLoS One 2009;4:e7695.

8. Gnerlich JL, Deshpande AD, Jeffe DB, et al. Elevated breast cancer mortality in women younger than age 40 years compared with older women is attributed to poorer survival in early-stage disease. J Am Coll Surg 2009;208:341-7.

9. Maggard MA, O'Connell JB, Lane KE, et al. Do young breast cancer patients have worse outcomes? J Surg Res 2003;113:109-13.

10. Yu KD, Wu J, Shen ZZ, et al. Hazard of breast cancerspecific mortality among women with estrogen receptorpositive breast cancer after five years from diagnosis: implication for extended endocrine therapy. J Clin Endocrinol Metab 2012;97:E2201-9.

11. Petrelli F, Coinu A, Cabiddu M, et al. Five or more years of adjuvant endocrine therapy in breast cancer: a metaanalysis of published randomised trials. Breast Cancer Res Treat 2013;140:233-40.

12. Burstein HJ, Temin S, Anderson H, et al. Adjuvant endocrine therapy for women with hormone receptorpositive breast cancer: american society of clinical oncology clinical practice guideline focused update. J Clin Oncol 2014;32:2255-69.

13. Kennecke HF, Olivotto IA, Speers C, et al. Late risk of relapse and mortality among postmenopausal women with estrogen responsive early breast cancer after 5 years of tamoxifen. Ann Oncol 2007;18:45-51.

14. Kim HA, Lee JW, Nam SJ, et al. Adding Ovarian Suppression to Tamoxifen for Premenopausal Breast Cancer: A Randomized Phase III Trial. J Clin Oncol 2020;38:434-43.

15. Burstein HJ, Lacchetti C, Anderson H, et al. Adjuvant Endocrine Therapy for Women With Hormone ReceptorPositive Breast Cancer: American Society of Clinical Oncology Clinical Practice Guideline Update on Ovarian Suppression. J Clin Oncol 2016;34:1689-701.

16. Francis PA, Pagani O, Fleming GF, et al. Tailoring Adjuvant Endocrine Therapy for Premenopausal Breast Cancer. N Engl J Med 2018;379:122-37.

17. NCCN. The NCCN Guidelines Version 1.2019 Breast Cancer Screening and Diagnosis. 2019. Available online: http://www.nccn.org/professionals/physician_gls

18. Perrone F, De Laurentiis M, De Placido S, et al. Adjuvant zoledronic acid and letrozole plus ovarian function suppression in premenopausal breast cancer: $\mathrm{HOBOE}$ phase 3 randomised trial. Eur J Cancer 2019;118:178-86.

19. Gnant M, Mlineritsch B, Stoeger H, et al. Zoledronic acid combined with adjuvant endocrine therapy of tamoxifen versus anastrozol plus ovarian function suppression in premenopausal early breast cancer: final analysis of the Austrian Breast and Colorectal Cancer Study Group Trial 12. Ann Oncol 2015;26:313-20.

20. Moher D, Liberati A, Tetzlaff J, et al. Preferred reporting items for systematic reviews and meta-analyses: the PRISMA statement. PLoS Med 2009;6:e1000097.

21. Julian PT Higgins SG. Cochrane Handbook for Systematic Reviews of Interventions V5.2. (updated June 2017) Available online: http://www.cochranelibrary.com

22. Higgins JP, Altman DG, Gotzsche PC, et al. The Cochrane Collaboration's tool for assessing risk of bias in randomised trials. BMJ 2011;343:d5928.

23. Higgins JP, Thompson SG, Deeks JJ, et al. Measuring inconsistency in meta-analyses. BMJ 2003;327:557-60.

24. DerSimonian R, Kacker R. Random-effects model for meta-analysis of clinical trials: an update. Contemp Clin Trials 2007;28:105-14.

25. Regan MM, Pagani O, Fleming GF, et al. Adjuvant treatment of premenopausal women with endocrineresponsive early breast cancer: design of the TEXT and SOFT trials. Breast 2013;22:1094-100.

26. Gnant M, Mlineritsch B, Schippinger W, et al. Endocrine therapy plus zoledronic acid in premenopausal breast cancer. N Engl J Med 2009;360:679-91.

27. Coleman R, Hall A, Albanell J, et al. Effect of MAF amplification on treatment outcomes with adjuvant zoledronic acid in early breast cancer: a secondary analysis of the international, open-label, randomised, controlled, phase 3 AZURE (BIG 01/04) trial. Lancet Oncol 2017;18:1543-52.

28. Cuzick J, Sestak I, Baum M, et al. Effect of anastrozole and tamoxifen as adjuvant treatment for early-stage breast cancer: 10-year analysis of the ATAC trial. Lancet Oncol 2010;11:1135-41.

29. Francis PA, Regan MM, Fleming GF, et al. Adjuvant ovarian suppression in premenopausal breast cancer. $\mathrm{N}$ Engl J Med 2015;372:436-46.

30. Masuda N, Sagara Y, Kinoshita T, et al. Neoadjuvant anastrozole versus tamoxifen in patients receiving goserelin for premenopausal breast cancer (STAGE): a double-blind, randomised phase 3 trial. Lancet Oncol 2012;13:345-52.

31. Ribi K, Luo W, Bernhard J, et al. Adjuvant Tamoxifen Plus Ovarian Function Suppression Versus Tamoxifen Alone in Premenopausal Women With Early Breast Cancer: Patient-Reported Outcomes in the Suppression of Ovarian Function Trial. J Clin Oncol 2016;34:1601-10. 
32. Bernhard J, Luo W, Ribi K, et al. Patient-reported outcomes with adjuvant exemestane versus tamoxifen in premenopausal women with early breast cancer undergoing ovarian suppression (TEXT and SOFT): a combined analysis of two phase 3 randomised trials. Lancet Oncol 2015;16:848-58.

33. Ganz PA, Greendale GA, Petersen L, et al. Breast cancer in younger women: reproductive and late health effects of treatment. J Clin Oncol 2003;21:4184-93.

34. Liu X, Qu H, Cao W, et al. Efficacy of combined therapy of goserelin and letrozole on very young women with

Cite this article as: Meng J, Wang X, Guan Y, Zhang D. Aromatase inhibitors plus ovarian function suppression versus tamoxifen plus ovarian function suppression for premenopausal women with early stage breast cancer: a systematic review and meta-analysis. Ann Palliat Med 2020;9(4):2294-2302. doi: 10.21037/apm-20-488A advanced breast cancer as first-line endocrine therapy. Endocr J 2013;60:819-28.

35. Carlson RW, Theriault R, Schurman CM, et al. Phase II trial of anastrozole plus goserelin in the treatment of hormone receptor-positive, metastatic carcinoma of the breast in premenopausal women. J Clin Oncol 2010;28:3917-21.

36. Pistelli M, Mora AD, Ballatore Z, et al. Aromatase inhibitors in premenopausal women with breast cancer: the state of the art and future prospects. Curr Oncol 2018;25:e168-75. 